\title{
A Robot Application for Analysis, Survey and Conservation of Historical Architectures
}

\author{
Michela Cigola and Marco Ceccarelli \\ University of Cassino \\ Italy
}

\section{Introduction}

This work is the result of the collaboration between DART (Laboratory of Documentation, Analysis, Survey of Architecture and Territory) and LARM (Laboratory of Robotics and Mechatronics) which, despite their apparent differences in terms of fields of research, for years have found time and motivations for opinion exchanges and cultural contacts, as well as research topics on which to begin genuine and fertile collaborations (Ceccarelli, et al., 2002) (Cigola, et al., 2005) (Cigola \& Ceccarelli, 2006).

The project research group is made up as follows: for the DART Laboratory of Documentation, Analysis, Survey of Architecture and Territory: Michela Cigola, architect specialized in Restoration of Monuments, full professor director of DART; Assunta Pelliccio, architect, assistant professor; Sara Mattei, engineer, PHD student; for the LARM Laboratory of Robotics and Mechatronics: Marco Ceccarelli, engineer, full professor director of LARM, Giuseppe Carbone, engineer, assistant professor; Erica Ottaviano, engineer, assistant professor; Chiara Lanni, engineer, research assistant.

Our goal is to analyse the characteristics and problems that are related to the analysis and conservation of historical architecture, within an innovative approach with robotised systems. The design requisites and the distinctive aspects of the operations of a large range of robotised systems have now been fully defined and investigated. However, there are very few precedents for such specialized application, moreover, in connection to the subject of historical architecture that is apparently far away from general areas of robotics and mechatronics.

The case of study that is presented here, namely the pre-Cosmatesque floor of the abbatial basilica of Montecassino, is a good case to highlight the flexibility of robotics and possible interactions with architecture, particularly in the field of surveying. Thus, this research focuses specifically on the application of robotic systems in the study and survey of ancient floor surfaces, although the wider purpose is to study and refine robotized systems and automated procedures to develop activities and results in the analysis phase and for the safeguard and conservation of historical architectural sites at large.

Robots are used more and more frequently in difficult situations, such as inspections of internal sites of atomic stations, space travel and exploring inaccessible terrestrial sites, as volcanic craters. Thus, a new and different example could be the analysis and safeguard of historical architecture through the use of self-propelled robots performing highly complex tasks on various kind of surfaces under the supervision of a human operator. 
Therefore, a proposal, is to develop a relationship between robotics and architecture, through a mehanical project that is especially studied and refined for analysis and architectural restoration. This is an extremely innovative application in the field of robotics, since it involves attempts to make a robot perform many architectural surveying actions through automated operations that can improve procedures and results, in terms of speed and accuracy.

\section{Architectural survey}

It is not easy to give a stict definition of architectural surveying, although now it is seem unanou,esily considered that it is not merely a simple instrument that is useful for other disciplines, but rather it is an autonomous operation with its own intrinsic value.

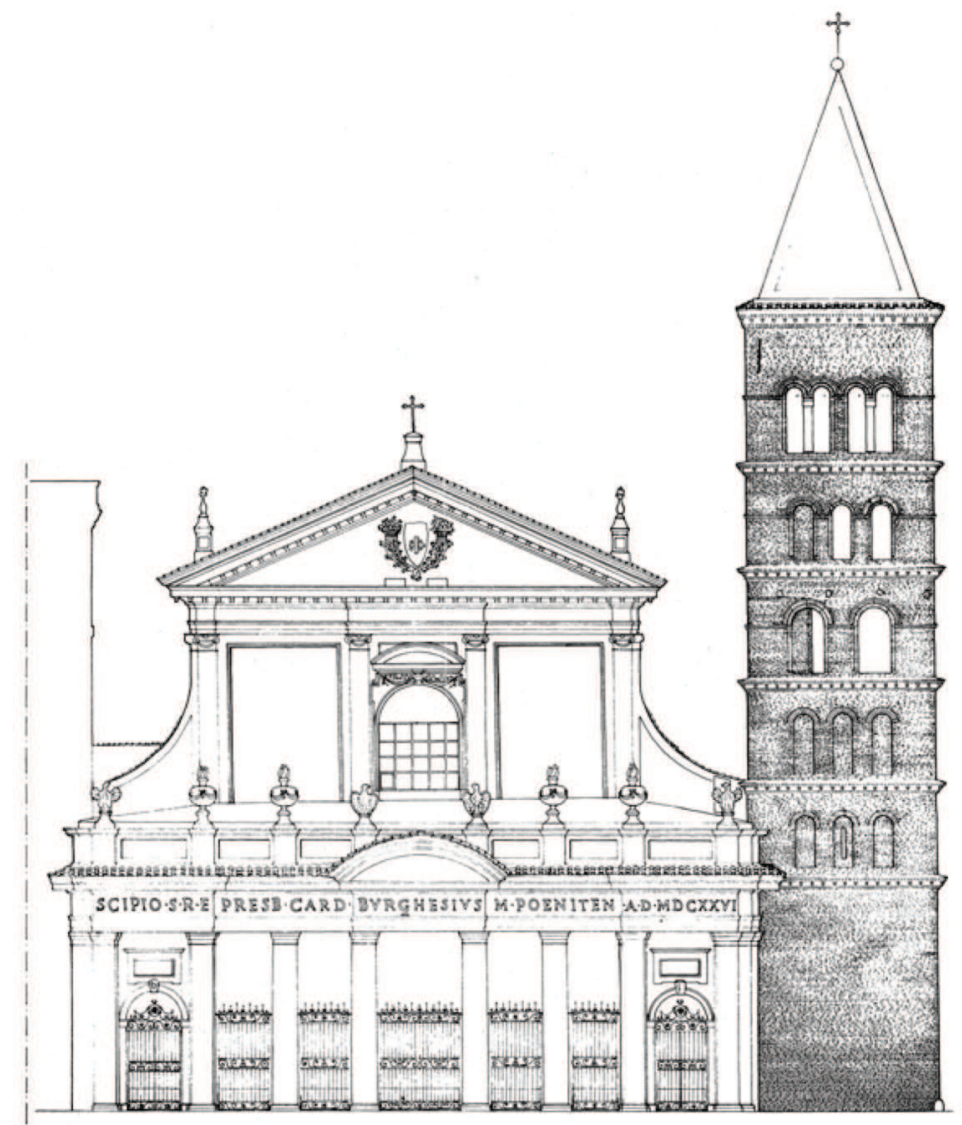

Fig. 1. Front side of the church of S.Crisogono, Rome. Survey by M. Cigola.

Surveying is now recognised as a complex discipline in its own right, the only one capable of penetrating the deepest and most hidden nature of an architectural organism, bringing to light the historical events of which it has been protagonist, original form and subsequent transformations over different eras, and providing us with full graphical imagery. 
Performing a survey means a fully understanding the metrical, geometrical and historical aspects of an architectural work, enabling you to reach a critical interpretation of it. A vast series of operations is required for this, above and beyond mere measuring.

The surveying process involves measuring, drawing, checking and comparing the data collected, highlighting similarities and differences using an accurate philological method. Alongside this phase, for a more complete understanding of the building it is essential to carry out a historical-archive study to perfectly identify its era.

Thus, surveying involves a complex series of operations, including the collection, checking and interpretation of all possible data, not only in terms of the geometric-spatial form of the architectural work, but also its construction, structural and historical data.

The fields in which surveying is used more and more often are historical-critical analysis of architecture and restoration. An accurate historical analysis of a work requires precise measuring techniques. The survey of a building is not a document used afterwards, but is an integral part of the process of historical-critical knowledge. Only through the close relationship that is formed between the works and the surveyor it is possible to gain real knowledge of a building.

As we have seen, surveying is an autonomous discipline, independent of its specific operational purpose. Nevertheless, individual applications may require particular methodological orientation.

A survey carried out before restoration work must lead to an overall understanding of the work under examination, completely exhaustive in terms of dimensional, structural and construction aspects. It must reveal the state of health of a building, its conditions of decay and static conditions.

The survey must bring to light historical, technical and diagnostic aspects; contribute to identifying the design intentions, from proportioning of metrological aspects, guiding historical research through iconographic, bibliographical and archive sources.

The problems involved in surveying for safeguard mainly highlight the need to acquire a great quantity of information to be integrated. Measuring must be carried out precisely and the graphical representation must give precise details of the characteristics of the works and all of its distinctive features, often through larger scales than those usually used in general preliminary surveys.

In order to carry out this task at maximum levels of what, a survey for restoration should use all modern available methodologies and techniques. There has been a recent revolution in this sector thanks to the development of 3D Scanning. This now well-known procedure consists of scanning the object using a 3D Scanner, which emits a laser or other type of ray to process the response data to determine the three-dimensional position of each material point that is hit by the ray. This innovative technology thus allows to create virtual 3D models of large and complex objects with remarkable levels of definition; recent trials have been conducted on several famous monuments including the Coliseum, the Pantheon, Saint Sophia's in Istanbul, etc. by RADAAR Department, School of Architecture at Rome University "La Sapienza" directed by prof. Mario Docci.

The following words are useful for a suitable definition of the process of architectural surveying as a prelude to restoration work: "surveying is a kind of non-destructive investigation into the works for restoration purposes. It is almost a clinical test, a kind of biopsy, which is not a mere clinical observation, yet not quite a surgical operation" (Carbonara, 1989). 


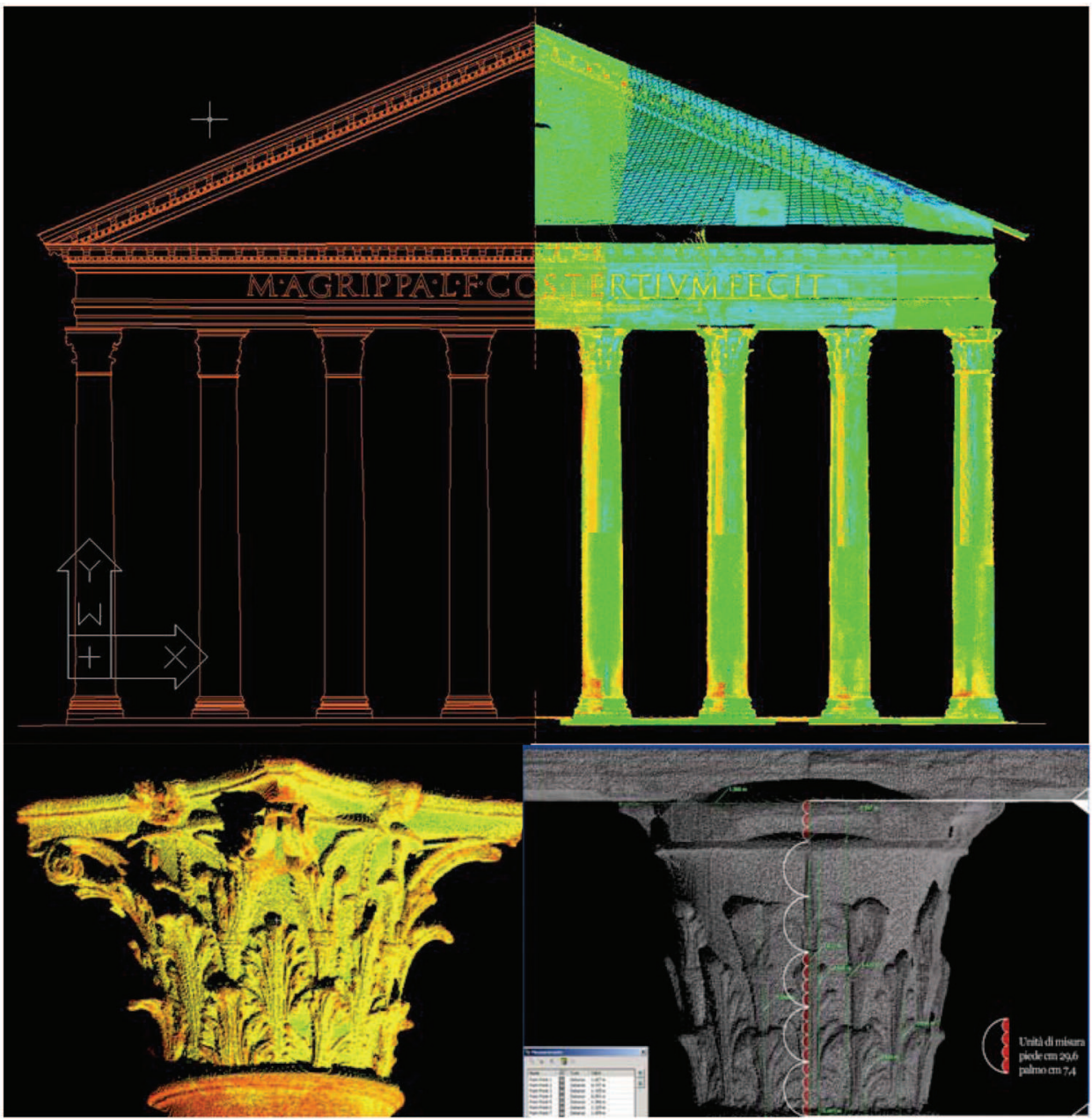

Fig. 2. 3d Laser Scanner Survey of Pantheon, Rome (PHD Thesis By P. Paolini, RADAAR Department, Rome University “La Sapienza").

\section{Architectural survey of historical pavements}

In the area of historical floor surfaces, we will concentrate our attention on Cosmatesque floors, of which the first example was the one in the abbatial basilica of Montecassino built in the 11th century, which, after a few decades, is followed by a large number of examples in Italy and in Europe over the next few centuries.

The Cosmatesque school began in the 12th century and mainly operated in Rome until the end of the 14th century; however, in addition to Rome, the art of the Cosmati masters spread throughout central and southern Italy and even reached England. The popularity of their technique covered a vast chronological period; indeed the first Cosmatesque work dates back to around 954, and the last to 1458. The period between the end of 14th and start of the 
15th centuries saw the great ferment that led to the great Renaissance season and the decline of the Cosmati masters, who were not clearly defined as being somewhere between craftsmen and designers.

The most eye-catching feature of a Cosmatesque floor is certainly the central strip, which leads from the entrance of the church directly to the apse. The simplest type of central strip is made up of a series of rotae or porphyry discs stemming off strips of mosaic alternating with strips of white marble. This shape became increasingly complicated until it created a very intricate design; another very common design for the central part of the floor is the socalled quincunx, which is a square design that includes a central rota surrounded by four more, all connected by strips of mosaic and marble. Often these types of central strips were combined to form extremely complex elements.

After establishing the central decorative motif, they went on to cover the entire floor surface with rectangles whose geometrical design was usually repeated symmetrically to the longitudinal axis of the central design, with greater attention paid to the general effect of the overall surface rather than the panel in itself (Cigola, 1993).
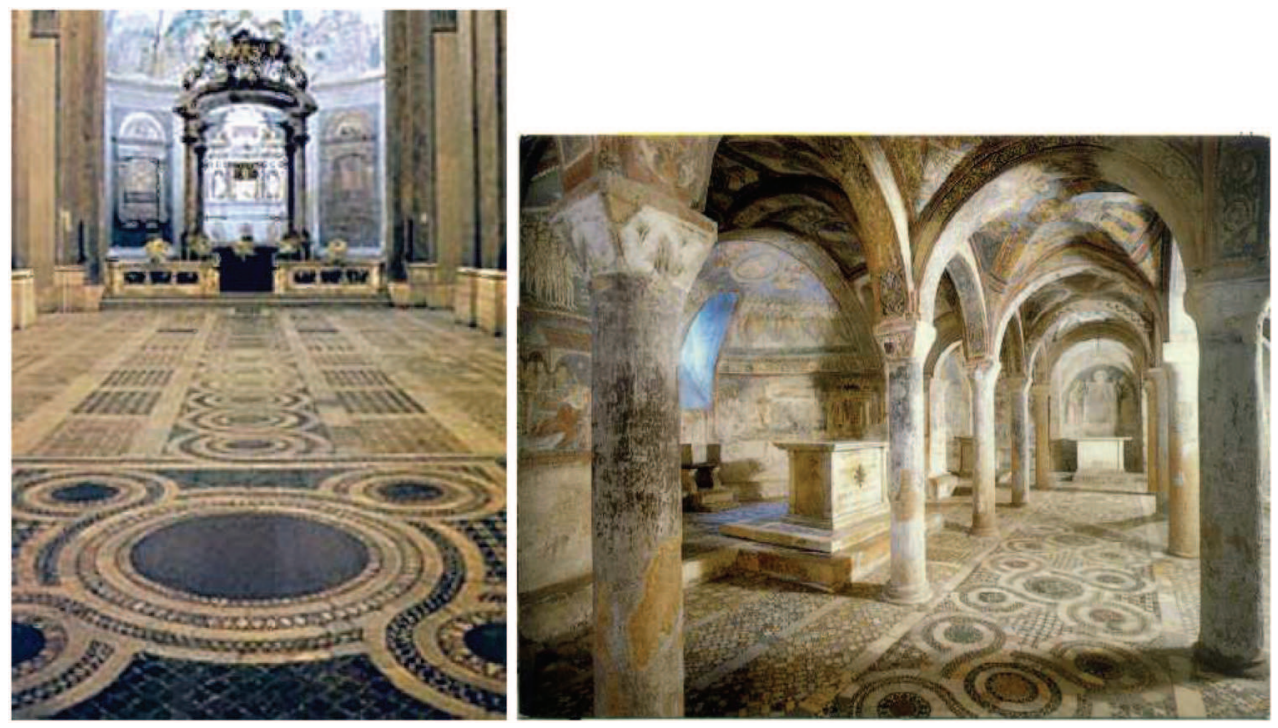

Fig. 3. Cosmatesque pavements. Basilica of S. Croce in Gerusalemme, Rome and Cathedral of Anagni.

The materials that were used for the floor surface were usually red or green Serpentine porphyry, and white, ancient yellow and pavonazzetto marbles, used indiscriminately. The brightest colours were usually reserved for the central strip, while the lighter colours were used in the more peripheral parts of the composition. In addition to aesthetics, there were certainly valid practical criteria for the choice of materials and colours, such as the availability of marble, porphyry and granite in Rome. Indeed the elements of an ancient classical floor often underwent numerous re-uses before reaching the fragmentation of Cosmatesque mosaics. It is not unlikely that this fragmentation prevented further re-use of the marble pieces in Cosmatesque floor, which have reached us almost intact (Glass, 1980). 
In addition to the marble fragments of various colours, one of the main recycled elements in a Cosmatesque floor is the porphyry rota, i.e. the large disc of green or more often red porphyry inserted to act as a greater vehicle of symbolic meaning. It is likely that the main reason for its use was the great availability of columns from columns the Roman empire, which were cut into slices, allowing floor surface arrangements with great decorative effect and fast to achieve (Guidobaldi \& Guiglia Guidobaldi, 1983).

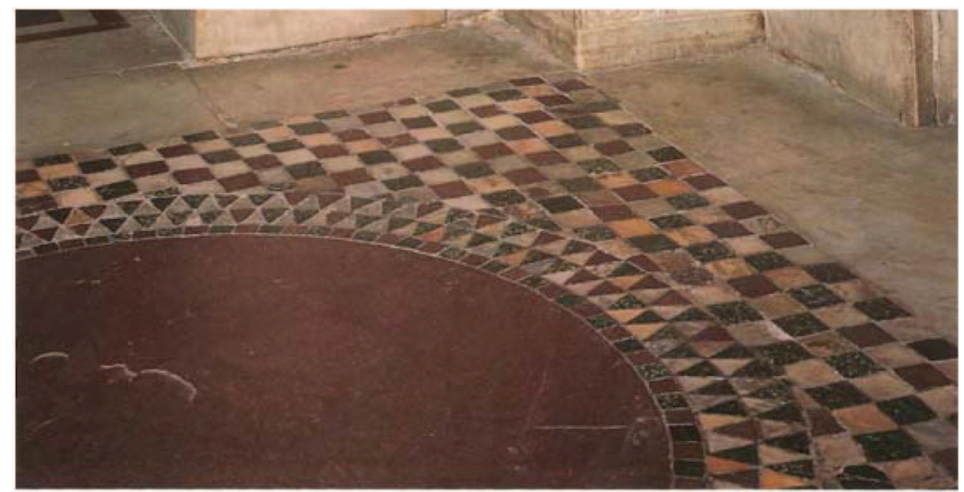

Fig. 4. Porphyry rota in the pavement of S. Prassede, Rome (Claussen, 1992).

In terms of the methods and techniques that are used to document Cosmatesque floor mosaics, surveys of works of this kind require special measuring and representation techniques, since the tiles forming the image have varying dimensions according to the overall design and the group of marble cutters responsible for creating them, and depending on the areas of floor. It is therefore necessary to highlight the equipment of the mosaic, highlighting the type of material used, the dimensions of the pieces laid, the degree and type of surface finishing, thickness and treatment of the jointing and the tile bed.

In a well-conducted survey, every element of the floor would be taken individually and in relation to the entire Cosmatesque floor, with particular attention for those elements that are repeated or make up a series, since any anomalies found in these series sometimes characterise the way a particular floor is laid. Great attention must also be paid to measuring of irregularities in the surface as a whole (repeated changes in level, sinkings etc.) in addition to identifying gaps, integrations added over time.

The entire process of measuring and graphical representation of a Cosmatesque floor mosaic can therefore be summed up in a series of operations, each of which must be performed at a different scale of representation: survey of the entire laying of the floor entered in diagram form in its architectural context; survey of composition elements forming the central strip; survey of all geometrical designs used in the sections that make up the greatest part of the floor mosaic.

Of course, each of these phases must include at least two more groups of images based on architectural survey mapping: the first is to detect decay, to highlight the degree and type of deterioration using specially conceived symbols; the second is for a chromatic survey of tones, grain and types of material.

To facilitate the entire process of operations and to have documentation of the state of the floor, it is useful to have a complete and exhaustive series of photographic before the survey itself (Cigola, 1993). 


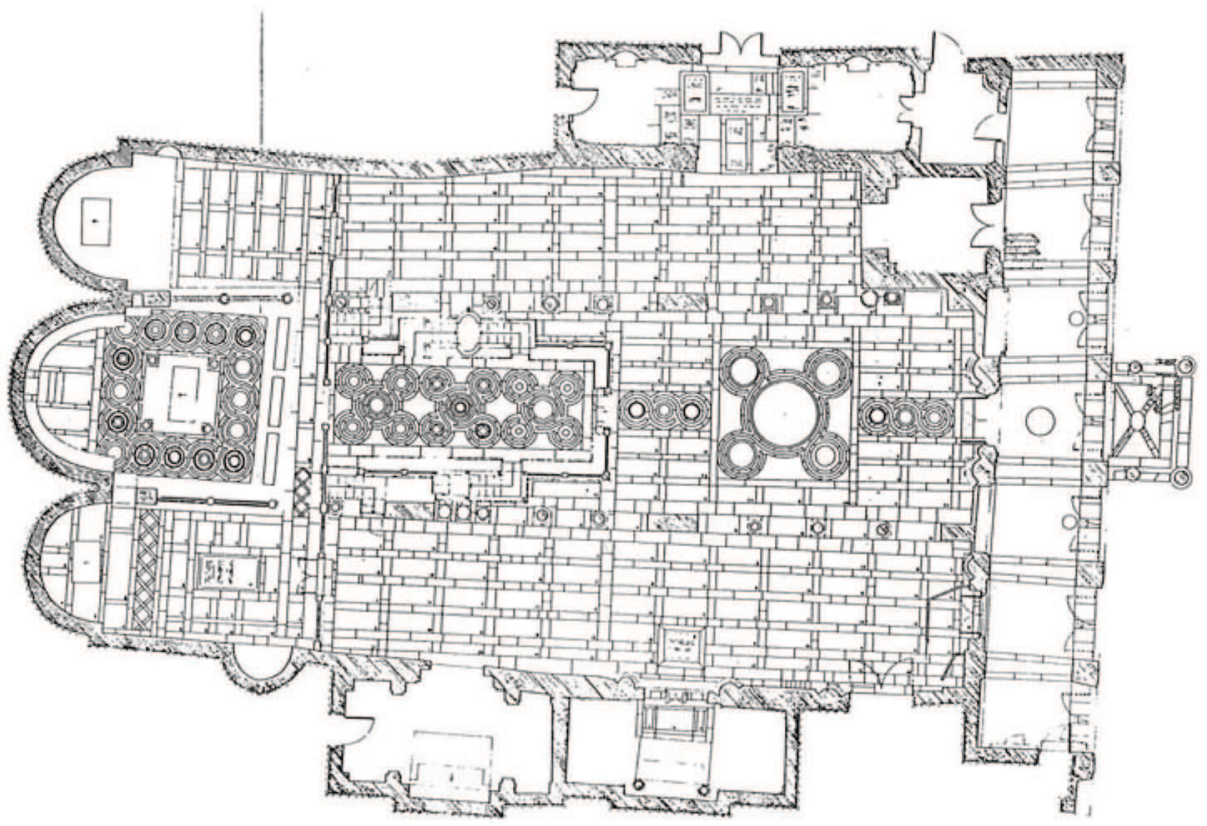

Fig. 5. Basilica of S.Maria in Cosmedin, Rome. Architectural survey of the cosmatesque pavement (1119-1130).

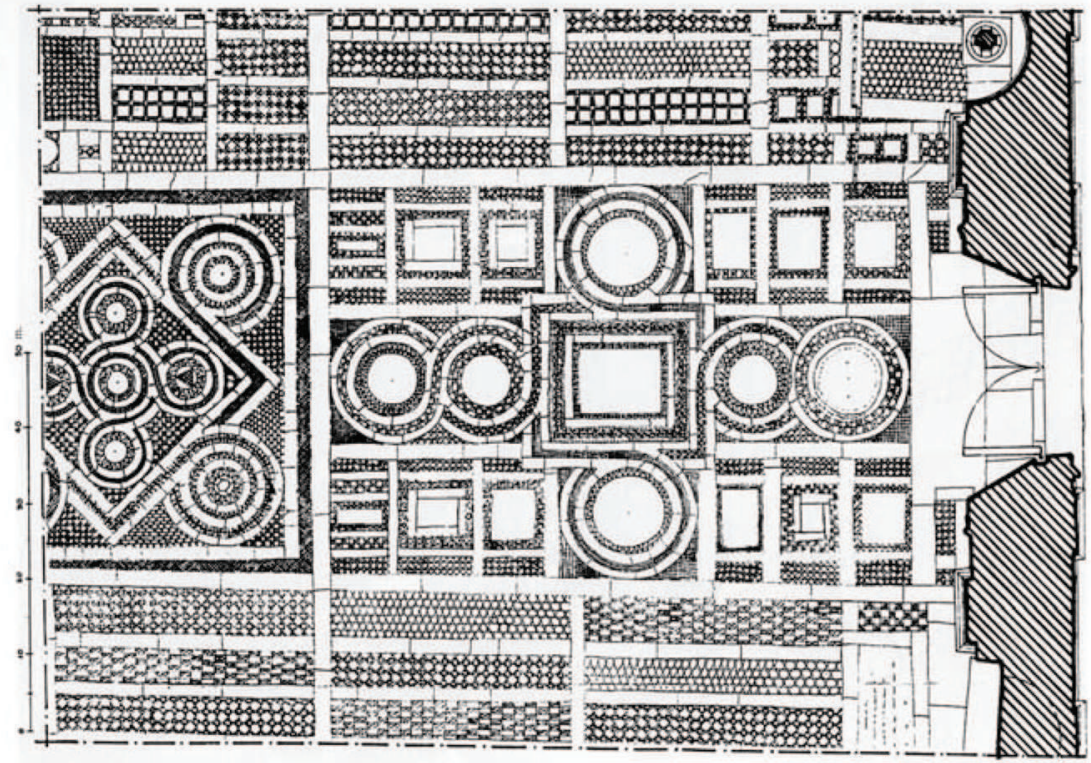

Fig. 6. Basilica of S.Crisogono, Rome. Architectural survey of the central strip of cosmatesque pavement (1146-1150). Survey by M. Cigola. 

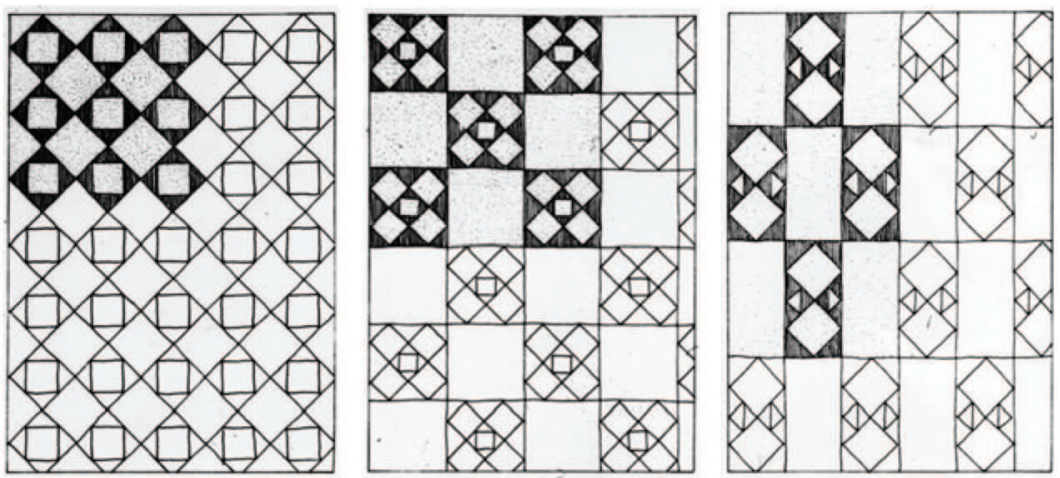

Fig. 7. Basilica of S.Crisogono, Rome. Architectural survey of rectangles and geometrical designs of the cosmatesque pavement (1146-1150).

Of course, each of these phases must include at least two more groups of images based on architectural survey mapping: the first is to detect decay, to highlight the degree and type of deterioration using specially conceived symbols; the second is for a chromatic survey of tones, grain and types of material.

To facilitate the entire process of operations and to have documentation of the state of the floor, it is useful to have a complete and exhaustive series of photographic before the survey itself (Cigola, 1993).

\section{Robot design and robotic operations}

Robots can be considered as the most advanced automatic systems and robotics, as a technique and scientific discipline, can be considered as the evolution of automation with interdisciplinary integration with other technological fields (Ceccarelli, 2004).

An automatic system can be defined as a system which is able to repeat specific operations generally with a low degree of intellectual and manipulative levels, but that can be easily programmed in agreement with demands of productivity.

It is worthy of note that an automatic system is generally able to perform one operation for which its mechanical structure has been designed. Aspects of flexibility depend on the possibility of reprogramming the control unit, which is generally able only to modify the time sequence of the designed operations. Therefore, an automatic system of industrial type can be thought of as composed of two parts:

- hardware with mechanical, electrical, pneumatic, and hydraulic components that provide the mechanical capability to perform an a priori-determined operation of movement and/or manipulation;

- control and operation counterpart with electronic components and software that provide the capability of autonomy and flexibility to the working of the system.

The two parts are essential in an automatic system and are integrated in the sense that their design and operation must be considered as a unique goal in order to obtain and operate an automatic system with the best performances. Therefore, an automatic system in which the hardware part is preponderant cannot have a suitable flexibility for a flexible production in agreement with the demands of productivity and market. In some cases these limited solutions are still required from productivity, when the product of a massive production is 
absorbed from the market with certain regularity during a period of time longer than the amortization time of the automatic system. Those systems with low flexibility are generally denominated as erigid automatic systems'. In Fig. 8 the variety of production systems is represented as a function of the productivity level.

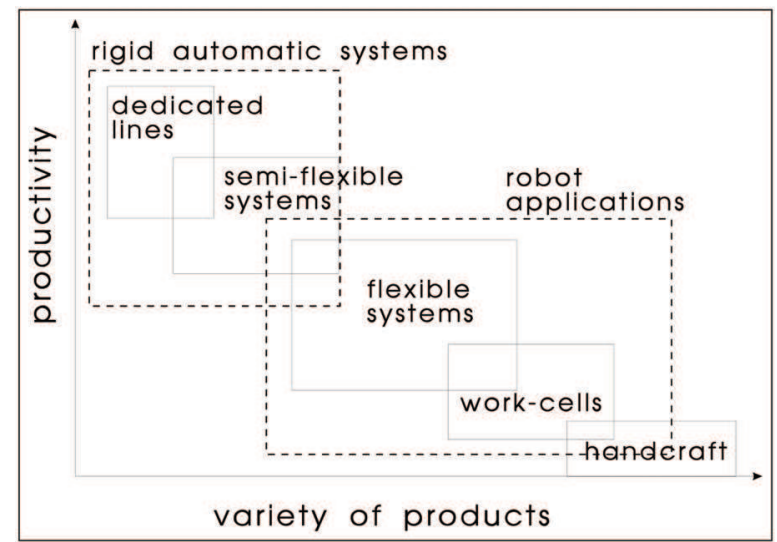

Fig. 8. Variety of automatic and robotized systems as functions of productivity level and product demand

In addition, it is worthy of note that a system with only the mechanical counterpart, although versatile, cannot be considered an automatic system since the updating of its operation is not obtained by means of control units. Such a system can be properly reprogrammed, but it requires the manual action of one or more human operators to change some components of the machinery or their running. Therefore, these systems can be properly named as machinery or mechanical systems.

Similarly, control systems cannot be considered as automatic systems, since they are not able to perform mechanical tasks, although they can be provided with a high level of flexibility in terms of re-programmability and memory capability. Therefore these systems can be properly named as control units or electrical-electronic-informatics systems.

A robot can be defined as a system which is able to perform several manipulative tasks with objects, tools, and even its extremity (end-effector) with the capability of being reprogrammed for several types of operations. There is an integration of mechanical and control counterparts, but it even includes additional equipment and components, concerned with sensorial capabilities and artificial intelligence. Therefore, the simultaneous operation and design integration of all the above-mentioned systems will provide a robotic system, as illustrated in Fig. 9.

In fact, more than in automatic systems, robots can be characterized as having simultaneously mechanical and re-programming capabilities. The mechanical capability is concerned with versatile characteristics in manipulative tasks due to the mechanical counterparts, and reprogramming capabilities concerned with flexible characteristics in control abilities due to the electric-electronics-informatics counterparts. Therefore, a robot can be considered as a complex system that is composed of several systems and devices to give:

- mechanical capabilities (motion and force);

- $\quad$ sensorial capabilities (similar to human beings and/or specific others);

- $\quad$ intellectual capabilities (for control, decision, and memory). 


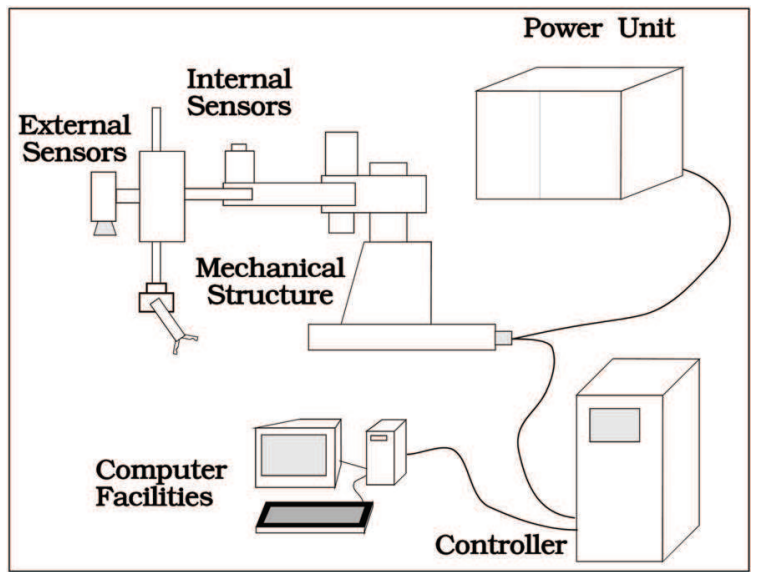

Fig. 9. Components of a robot

Initially, industrial robots were developed in order to facilitate industrial processes by substituting human operators in dangerous and repetitive operations, and in unhealthy environments. Today, additional needs motivate further use of robots, even from pure technical viewpoints, such as productivity increase and product quality improvements. Thus, the first robots have been evolved to complex systems with additional capabilities.

Nevertheless, referring to Fig. 9, an industrial robot can be thought of as composed of:

- a mechanical system or manipulator arm (mechanical structure), whose purpose consists of performing manipulative operation and/or interactions with the environment;

- sensorial equipment (internal and external sensors) that is inside or outside the mechanical system, and whose aim is to obtain information on the robot state and scenario, which is in the robot area;

- a control unit (controller), which provides elaboration of the information from the sensorial equipment for the regulation of the overall systems and gives the actuation signals for the robot operation and execution of desired tasks;

- a power unit, which provides the required energy for the system and its suitable transformation in nature and magnitude as required for the robot components;

- computer facilities, which are required to enlarge the computation capability of the control unit and even to provide the capability of artificial intelligence.

Thus, the above-mentioned combination of sub-systems gives the three fundamental simultaneous attitudes to a robot, i.e. mechanical action, data elaboration, and reprogrammability.

Consequently, the fundamental capability of robotic systems can be recognized in:

- mechanical versatility;

- re-programmability.

Mechanical versatility of a robot can be understood as the capability to perform a variety of tasks because of the kinematic and mechanical design of its manipulator arm.

Re-programmability of a robot can be understood as the flexibility to perform a variety of task operations because of the capability of its controller and computer facilities.

These basic performances give a relevant flexibility for the execution of several different tasks in a similar or better way than human arms. In fact, nowadays robots are 
wellestablished equipment in industrial automation since they substitute human operators in operations and situations, which are:

- dangerous - for manipulative tasks and/or unhealthy environments;

- $\quad$ repetitive - with low-level cultural and technical content;

- tiresome - for manipulative tasks requiring energy greater than that provided by a human operator;

- difficult - for human operators.

In addition, the use of robots is well-established in industrial production since robots are:

- $\quad$ versatile, as they have the ability to operate in different situations;

- useful for unhealthy or limited environments, which can be dangerous or unfeasible for human operators.

Besides the above-mentioned motivations of technical nature, robots and robotic systems are currently used with the aim of:

- decreasing production costs, which can be related to a better use of the machinery;

- increasing productivity, with an increase of the operation velocity;

- enhancing product quality, in terms of constant characteristics and improved manufacturing;

- achieving flexible production as a capability of rapid adjustment of production to required changes in manufacturing.

The mechanical capability of a robot is due to the mechanical sub-system that generally is identified and denominated as the emanipulator', since its aim is the manipulative task.

The term manipulation refers to several operations, which include:

- grasping and releasing of objects;

- $\quad$ interaction with the environment and/or with objects not related with the robot;

- movement and transportation of objects and/or robot extremity.

Consequently, the mechanical sub-system gives mechanical versatility to a robot through kinematic and dynamic capability during its operation.

In general, in order to perform similar manipulative tasks as human operators, a manipulator is composed of the following mechanical sub-systems:

- $\quad$ an arm, which is devoted to performing large movements, mainly as translations;

- a wrist, whose aim is to orientate the extremity;

- $\quad$ an end-effector, which is the manipulator extremity that interacts with the environment. It is worthy of note that although the mechanical design of a manipulator is based on common mechanical components, such as all kinds of transmissions, the peculiarity of a robot design and operation requires advanced design of those components in terms of materials, dimensions, and designs because of the need for extreme lightness, compactness, and reliability.

The sensing capability of a robot is obtained by using sensors suitable for knowing the status of the robot itself and surrounding environment. The sensors for robot status are of fundamental importance since they allow the regulation of the operation of the manipulator. Therefore, they are usually installed on the manipulator itself with the aim of monitoring basic characteristics of manipulations, such as position, velocity, and force. Additionally, an industrial robot can be equipped with specific and/or advanced sensors, which give human-like or better sensing capability. Therefore, a great variety of sensors can be used, to which the reader is suggested to refer to in specific literature.

The control unit is of fundamental importance since it gives capability for autonomous and intelligent operation to the robot and it performs the following aims: 
- regulation of the manipulator motion as a function of current and desired values of main kinematic and dynamic variables by means of suitable computations and programming;

- $\quad$ acquisition and elaboration of sensor signals from the manipulator and surrounding environment;

- capability of computation and memory, which is needed for the above-mentioned purposes and robot re-programmability.

In particular, an intelligence capability has been added to some robotic systems concerned mainly with decision capability and memory of past experiences by using the means and techniques of expert systems and artificial intelligence. Nevertheless, most of the current industrial robots have no intelligent capability since the control unit properly operates for the given tasks within industrial environments. The control systems that are used in robots can be classified as:

- electro-mechanical sequencer units with end-stroke stops; units with pneumatic logic; electronic units with logic; PLC (Programmable Logic Controller) units;

- micro-processors;

- minicomputers;

- computers.

Indeed, nowadays industrial robots are usually equipped with minicomputers, since the evolution of low-cost PCs has determined the wide use of PCs in robotics so that sequencers, which are going to be restricted to PLC units only, will be used mainly in rigid automation or low-flexible systems.

\section{Requirements and problems for robots in Survey applications}

Survey and Analysis activity on historical architectonic goods are generally carried out with manual operations with few assisting devices. In addition, the activity is differentiated in Architecture and History of Art not only for the differences of the goods in terms of materials and structure types, but at the most for the scale of the dimensions of the objects of study. In general they are buildings or large parts of them in Architecture, and small components of buildings or decorative details of them. Survey activity is aimed to detect details of the historic works both in terms of dimensions and details for the different interests in a historical Analysis. Thus, there are several aspects that may differentiate the activity in Architecture Survey for the scale of the objects unders examination. Nevertheless, there are also several aspects in common, mainly in the approaches for the activity in getting knowledge and experiences of the objects under examination in Survey and Analysis activity. They are related to tasks, which can be often repetitive, for acquiring data from the historic works, both in terms of dimensions and figures of details. Those repetitive tasks are some time performed with the assistance of devices that help in achieving proper repetitions and acquisition data with regular characteristics. But often those assisting devices are developed or even adapted for a specific case without a general frame of operations, so that each use can require several attempts and mainly understanding for a proper operation. The aim of using robotic systems is to define a general approach both for design and operation of suitable assisting devices with a proper level of automation and robotic characteristics, by starting from the fact that assisting devices are already used and even well accepted by Survey operators and investigators. 
Main problems in Survey activity that can be enhanced with suitable assisting robotic devices, can be identified in data acquisition of dimensions and figures of the historical works. Dimensions can measured by using proper sensors and even movement actions of automatic mechanical systems; while figures of the historical works can be detected by proper location of the instrumentation that can be adjusted properly with those assisting robotic devices. There are several cases and situations in which those measuring activity and figure acquisition cannot be performed by human operators, like for examples in no accessible sites (for lack of space and/or human safe environments), but even for obtaining proper resolution of the results (for example, when the object is not at the hand or the work is fragmented). In addition, a certain automation of current manual operation in Survey can help to get results in short time and with more accurate results. Another important aspect of the current activity is a certain fragmentation of the main phases that a Survey activity can have, namely, preliminary polishing of the historic site and/or work, identification of main frames, identification of main parameters, determination of the Survey problem, choice of instrumentation, calibration of the instrumentation, campaign of acquisition data, elaboration of the data, interpretation of the data, analysis of the results, and so on.

Typical Survey on-field activity $n$ Architecture can be recognized in measuring dimensions of the works, detecting their general figures in term of shapes and volumes, acquiring images or even videos both for the general status and details, inspecting structure of the works in terms of materials and construction process, and deducting in several cases even samples of the works for further investigations. Most of these activities can be helped with assisting robotic devices and they can be even more successfully both in term of productivity and quality of results. One additional aspect, that is more and more important, is related to a request of shortening the Survey activity that most of the cases require to close the historical goods to the public visit. The possibility to have assisting robotic devices that can operate not only in short time, but even without requiring large frames obscuring the historical goods is a strong demand. For example a Survey activity on the Coliseum in Rome, in general will require scaffolding that will cover the whole monument for long time at least both for the installation and disassembly of the scaffolding. The possibility to use a robotic system, which can climbing the walls of Coliseum with proper instrumentation, could reduce and even avoid any heavy scaffolding cover of the monument during the Survey operation. In general, Survey activity in terms of measuring dimensions require scaffolding and/or other structures that not only avoid the access to the good but may not permit any other action even for the Survey and Analysis activity on the historical work. Similarly the activity for data acquisition require to bring suitable instrumentation near the details of the good under examination with inconvenience in mobility and accessibility of other systems and human operators. Even the direct inspection by human operator can require heavy infrastructures and safety requirements that can make even more complicate the operations. Alternative solutions can be attempted with mechanical or robotic systems for tele-operations and image recording or transmission by using suitable mobile systems. Main problems for which it can be thought useful to get experience with innovative solutions using automatic mechanical systems and robots, can be identified as specifically related to details works in hiostorical architectonic goods in terms possibility to facilitate or even to complete capability of a human operator like for example:

a. high-resolution image acquisition of surfaces with the aim of a detailed graphical reconstruction and exegetic interpretation; 
b. identification of details and their location within the plan of the work in which they are located;

c. representation and reconstruction of work images that are on curved surfaces or in hidden surfaces;

d. acquisition of images with suitable static mechanisms that are not available with current photographic means both for the light sources and the camera location with respect to orthogonally of work surface;

e. possibility to use additional instrumentation, even in one unique campaign/action of Survey;

f. possibility to use the robot performance for additional evaluations and computations of work characteristics.

Main problems of an application of robots in Survey activity can be outlined as related to development of design methodologies and solutions for mechanical and robotic systems that can be operated by users who are experts in Survey and Analysis of cultural goods of historic interest. In addition, the feasibility of those proposed robot solutions should be validated through specific prototypes for specific operations on site.

The cooperation in the above-mentioned fields of Robotics, and Architecture Survey is challenging since it addresses integration of approaches and methodologies that, in general, they do come across to each other because they are from different cultural communities (engineers, architects, and historians). Therefore, the robot application is aimed to introduce innovative approaches and methodologies in activity for survey and study of the history of the past by using mechanical systems and automatic/robotic systems with an expected positive impact for improving the quality of survey and study activity and in establishing a frame for the formation of new figures of professionals both in engineering and survey/restoration areas. A important aspect can be recognize in developing an interdisciplinary frame through integrated methodologies and solutions for design and operation of advanced systems in the fields of activity of maintenance and study of monumental historical goods and historical works. Indeed, a solution for cultural barriers among engineers, architects, and historians can be an important challenge for a long-term application of robots in Survey activity. In addition, this interdisciplinary can give the possibility to establish new research areas and even a new professional figures with multidisciplinary aspects. Even the specific area of Service Robotics will benefit of the possibility to have a new field of applications. Indeed, new horizons for research and professional figures can be outlined in activity that can be carried out with integrated multidisciplinary expertise but even with a specialization in one of the three abovementioned areas with a multidisciplinary view.

Therefore, a general methodology for the robot application in Survey can be described as a sequence of steps for integrating the above-mentioned areas to outline an approach for design and operation both of mechanical and robotic systems, and Survey activity. Nevertheless, each area will also work with traditional methodologies of its fields mainly with the aim to define and achieve successful implementation of the results of the robot applications. In particular, in Robot Engineering the problems can be approached by starting with an analysis of the State-of-Art of service robots and assisting robotic devices that could be near to Survey applications; studying the peculiarities of the robot applications as outlined by problems in Architecture Survey; formulating design problems and operation strategies by taking into account both technical and cultural aspects; elaborating solutions 
for a general procedure and then for specific cases as test-bed applications; constructing and testing prototypes of systems and operations with consideration of constraints and instrumentation in Survey applications for general strategies and even for the specific testbeds. In these aspects technical methodologies, that are based on suitable models in terms of mechatronics and mathematical formulation, can be developed towards technical solutions with technical descriptions, which are typical of Engineering fields. Nevertheless, great attention can be addressed to include aspects from the Survey activity even for facilitating understanding of the designed robotic systems and their operations by Survey operators. Indeed, great efforts will be spent for achieving user-oriented operation of the robotic systems that should be possible even without any supervision of engineers when in historical on-field sites. However, during the design process like in the test experimentation a strong interaction can be required with the team members from Survey area, but even with their presence and contribution in the engineering processes.

On the other hand, in Architecture Survey the Survey problems can be approached by reviewing the current State-of-Art of assisting devices and related operation strategies with the traditional approaches of the disciplines but even with a translation to engineering aspects; designing operations of Survey activity that can be performed with mechanical and robotic systems, with special emphasis to cases and situations in which their use could be determinant for an improvement of the productivity and quality of the works of Survey operators; elaborating test-bed operations for experimental validation of design systems by looking to specific aspects of Survey activity; designing adaptations of instrumentation and operations for Survey activity with mechanical and robotic systems; identifying field applications in which the results and designed robotic systems can be operated for a real Survey activity.

The development of robots for Survey applications can be programmed with a general plan through phases with the following outline:

1-st phase: definition of design requirements and operation characteristics

2-nd phase: development of methodologies and Survey strategies for design of mechanical and robotic systems

3-rd phase: development of methodologies and Survey strategies for operation of mechanical and robotic systems

4-th phase: construction of prototypes and test-bed applications

5 -th phase: tests and validations

The plan of each phase can be carried out with activity that can overlap and can continue even in next phases as described in the following. The core of the development planning can be considered in the phases 2 and 3 that in principle will have activity extended during the whole activity. The activity can be run by the two groups, namely Robot Engineering and Architecture Survey, in same aspects with parallel separate plans, but mainly with a joint program as outlined in the following at the whole.

1-st phase: definition of design requirements and operation characteristics

In this phase the work team can work to get knowledge and experience from the areas of each of the two groups with the aim to identify peculiarities and characteristics of Survey activity that can be devoted to mechanical and robotic systems. Each group can review the State-of-Art of its area by addressing special attention to those aspects that can be useful for an integration of the disciplines. In particular, aspects can be outlined as directed to define requirements and operation characteristics that are suitable for a certain automation or 
improvement by using assisting robotic devices. Current assisting devices and their operations can be reviewed in strict cooperation by the team members in order to identify those aspects that can be evolved as suitable for mechanical and robotic systems. The review work can be also aimed to reconsider the Survey activity from general viewpoints and then with a perspective of using mechanical and robotic systems as means within a cultural formation of new Survey operators. In Robot Engineering the aspects of service robots can be examined to search similarities and differences in existing solutions for other or similar applications that could better help to explain the possibility of implementing those systems in cultural frames that are not used to work with them. In this phase the two groups can work separately for some aspects and can exchange information with the aim to start some collaborative actions. The integrated activity can be thought even in preliminary experiences that can be carried to show to the other group the peculiarities of their work in traditional frames. Thus, robots and mechanical systems can be used for laboratory tests of simulated simple Survey operations and Survey operation can be even experienced on fields with the presence of engineers with the aim to show them the peculiarities of the manual operations and other actions that could be devoted to a certain mechanization and/or robotization. This phase can be characterized by an identification of possible applications through the determination of those characteristics that can be used as requirements and constraints for next design and operation activities. The understanding of those aspects can require strict collaboration among the groups even with the aim to achieve reciprocal understanding of terminology and needs for the Survey robotized activity.

2-nd phase: development of methodologies and Survey strategies for design of mechanical and robotic systems

In this phase the activity of the previous phase can be oriented specifically to design purposes for mechanical and robotic systems. Nevertheless, the design methodologies and approaches from robot engineering must be adjusted and integrated with the aspects coming from peculiarities and requirements for Survey activity, even with the aim to give the possibility to Survey researchers and operators to contribute in the design process. The design process can be focused on system architectures but also on Survey strategies that can be performed with them. The design process can be carried out to define problems from one aspect but even influencing other aspects with a team activity that can be scheduled with full integration of perspective and formulation in elaborating design procedures. In particular, design algorithms can be formulated for the design of mechanical and robotic systems by approaching the problems for the structure types, dimensional synthesis, mechanical design of parts, endowment of suitable internal and external instrumentation. In each of the mentioned design aspects, interference is expected with the cultural requirements for Survey activity. In this elaboration process, significant can be considered the activity of analysis and simulation of existing solutions and operations, both in numerical procedures and experimental tests. Thus, each group can be responsible to outline to the other groups results that can be used in design procedures for mechanical and robotic systems. A unification of the perspective can give the possibility to identify a design methodology that can be used with proper specific adaptation to each of the two views, namely robot engineering and architecture survey. Similarly, a design methodology can be elaborated for survey strategies with the aim to determine aspects and peculiarities that can be devoted or not to mechanical and robotic systems. In particular, situations and conditions of the on-field Survey activity can be redesigned towards a proper use of assisting robotic 
devices. The study of manipulations and other actions can be carefully analyzed with proper measures from different perspectives with the aim to identify design margins in rethinking the Survey procedures for general and specific tasks. Particular attention can be addressed to the cases in which human operators cannot work and therefore mechanical and robotic systems could be seen as the only solution for Survey activity. It is to note that this phase can include preliminary activity of the next phase since operation issues can be significant in defining design features both in term of robotic systems and Survey strategies. Indeed, although differentiated in the 2-nd and 3-rd phase the activity can be planned with strong interaction between system design and operation planning both the systems and Survey activity.

3-rd phase: development of methodologies and survey strategies for operation of mechanical and robotic systems

In this phase design activity can be directed specifically to the possibility of using robotic systems and Survey strategies that have been designed in the previous phase. Attention can be addressed to operation features in terms of system programming, system equipment, user-oriented facilities, human-machine interfaces that can determine a successful useroriented results for Survey operators. Similarly to the activity of previous phase, in this phase the design activity can be carried out through simulations and experiences to define procedures for the analysis and to conceive operation strategies jointly and separately for the systems and their use in Survey activity. Simulations can be carried out with numerical computations and even with laboratory experiences, within the specific frame of each research group and finally with an integrated view. Even Survey operations can be reconsidered for a proper design that can fit the possibility of the mechanical and robotic systems. Thus, actions and sensorization can be analyzed and considered for outlining requirements and constraints of the operation of the systems and Survey activity, in joint and separate perspectives. Indeed, the activity can run with a enlarged mechatronic approach that will include considerations, models, and whenever possible formulation from Architecture Survey.

4-th phase: construction of prototypes and study of applications

In this phase design results both for systems and operations can be applied for construction of prototypes. The prototypes can be a first construction of systems with full operation capability and Survey strategies in terms of activity planning for real operations. During the definition of the mechanical design and final arrangements of prototype designs, inputs can be considered from on going experiences and even on the progress of the integrated views for a mechatronic approach that include also cultural issue of Survey activity. Prototype construction can refer also to the operation strategies in term of suitable programming not only in term of robotic systems but even at the level of Survey planning. Applications on which the prototypes of systems and operation can be tested, can be defined with general frames, but also several specific applications can be studied and defined for testing the versatility of the new designed robotic systems and operations of new Survey strategies. Applications can be studied and planned at different scales of operation, namely from large Architecture areas up to single pieces of architectonic goods. In this phase the user-oriented solutions can be also experienced with prototypes that should have acceptance from the Survey operators. Therefore, contributions can be expected also in the activity of construction and adjustment of the design solutions, even through optimization of the design procedures and simulations that have been defined in the previous phases. The 
construction of prototypes permit a practical check of the fulfilment of the goals of the new desogns also in terms of easiness of transportability, manoeuvrability, handling, and adaptation in different Survey applications. In addition, during the construction of prototypes and definition of applications, emerging problems could be used for an optimization of the results and procedures that have developed in the previous phases, even as a consequence of a practical experience with solutions under construction.

5-th phase: tests and validations

In this phase the soundness of results can be proved with tests that can be carried out with the prototypes in laboratory experiences and finally in on-fields applications of Survey activity. Tests can be carried out with the aim to check and adjust the feasibility of the proposed prototypes for a user-oriented use of designed robotic systems and their operations by Survey operators. In this phase, the results of the tests and the feasibility of experienced applications in different environments and conditions can be still used to adjust the prototypes but even to optimize the design and operation procedures.

Novel aspects of the proposed robot application can be identified in the multidisciplinary cultural frame for identifying, designing, experiences engineering solutions for Survey in Architecture and History of Architecture, both in terms of new systems and new operation strategies. The idea of using robotic systems for Survey activity can also stimulate rethinking of current Survey practices not only as depending of the design goals of new systems but even for new approaches in Survey activity with or without assisting devices.

\section{Case study of the floor of Montecassino abbey}

For centuries one of the most important monuments in European architecture, Montecassino Abbey was not only a spiritual, cultural and artistic centre, but, during several periods of history, was also the organisational and economic centre of what was once the "land of Saint Benedict".

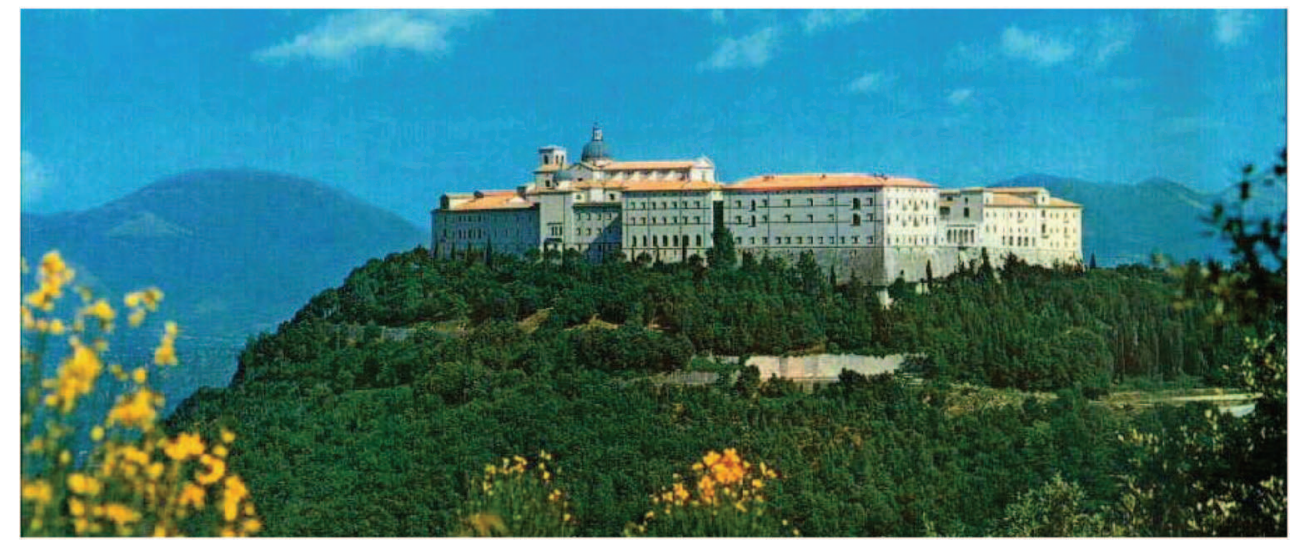

Fig. 10. The Abbey of Montecassino as it appears today after its reconstruction.

Saint Benedict arrived in Montecassino in 529, where he found the remains of what had once been a flourishing Roman town. In his Dialogues, Gregory the Great (Gregorio Magno, 1924) tells us that he destroyed the temple of Apollo and its Ares and set fire to the sacred woods to make room for what would be the first Benedictine monastery. 
The first destruction of the abbey, which was demolished and rebuilt, took place in around 581 by the Lombards. Rebuilt at the start of the 8th century, the monastery underwent a period of magnificence until 883 when it was devastated once again by the Saracens. Abbey life began again only after a century, when it was rebuilt in around 950.

In the 11th century, Montecassino went through the most splendid period of its history, when in 1058, the son of the prince of Benevento was elected abbot there. The new abbot, Desiderio, who later became Pope Victor III (1086-1087), began a period of great architectural works, such that at his death the monastery had been almost entirely rebuilt and in such a grandiose way that it stood head and shoulders in magnificence above anything else of its kind in the Western world of that era (Bertaux, 1904).

It was again destroyed by an earthquake in 1349, and in the subsequent centuries, every period of history has left a trace on the monument, although the great transformations of the 16th and 17th centuries left the deepest mark on the architectural story of the abbey, leaving us with a great Renaissance and Baroque monument, but obscuring the mediaeval works.

On 15 February 1944, the monastery was almost completely razed to the ground by ally bombs, leaving only the south-eastern corner of the building intact. Reconstruction work began a year later, and was officially completed on 25 October 1964, when the abbatial basilica was reconsecrated for the fourth time since its founding.

Despite all of the events of which it has been a protagonist, fourteen centuries of the Benedictine monastery at Montecassino, destroyed and rebuilt on several occasions, is neatly summed up in its coat of arms: an oak tree cut through completely, which reflourishes and above it the motto "succisa virescit".

This rapid summary of the historical background of the architectural complex of Montecassino has served to introduce the floor of its abbatial basilica, placed in the highest point of the monastery. Indeed, the pre-Cosmatesque floor surface of the basilica of Montecassino abbey is the specific case study for application of the robotized systems and automated procedures for architectural surveying.

In 1058, Desiderio of the Benevento princes was elected abbot of Montecassino and, in around thirty years of rule, brought the coenobium to the height of political, spiritual and artistic-architectural expansion. First as abbot and then as pope, retaining the abbotship after his election to the papacy (Cigola, 2005), he performed great architectural works in the monastery, which culminated in the reconstruction of the abbatial basilica. These works are recorded in a few mediaeval chronicles, where we learn that between 1066 and 1071 Desiderio brought artists specialised in mosaics and inlaying from Byzantium to cover the entire church floor with different varieties of marble (Hoffmann, 1980), mainly recovered from monuments in Rome. The new floor of the basilica of Montecassino marked the passage from ancient floor mosaics to mediaeval ones and marked the start of the great season of Cosmatesque art (Claussen, 1992).

Unfortunately, it is impossible to fully grasp the significance of the floor of Montecassino, as it is no longer visible (Della Marra, 1775). It was later covered by another marble inlay floor during the $18^{\text {th }}$ century and for a long time it was thought that it was lost, but we have an idea of what it was like from a few image representations and parts of it that have survived and have been re-laid in several chapels in the monastery.

The first is an $18^{\text {th }}$ century survey (Gattola, 1733) carried out with great care and attention to details, which presents all the elements that we find in Cosmatesque floors, of which the Montecassino floor is the first example. The imaging, included in the monumental work by 
Gattola, is dated Naples 1713 and signed by the inlayer Andreas Maliar. Originally carried out in large scale although destined, although later reproduced in smaller scale, it shows the entire mosaic surface in detail, perfectly replicating the geometric designs which, run alongside each other to form most of the surface.

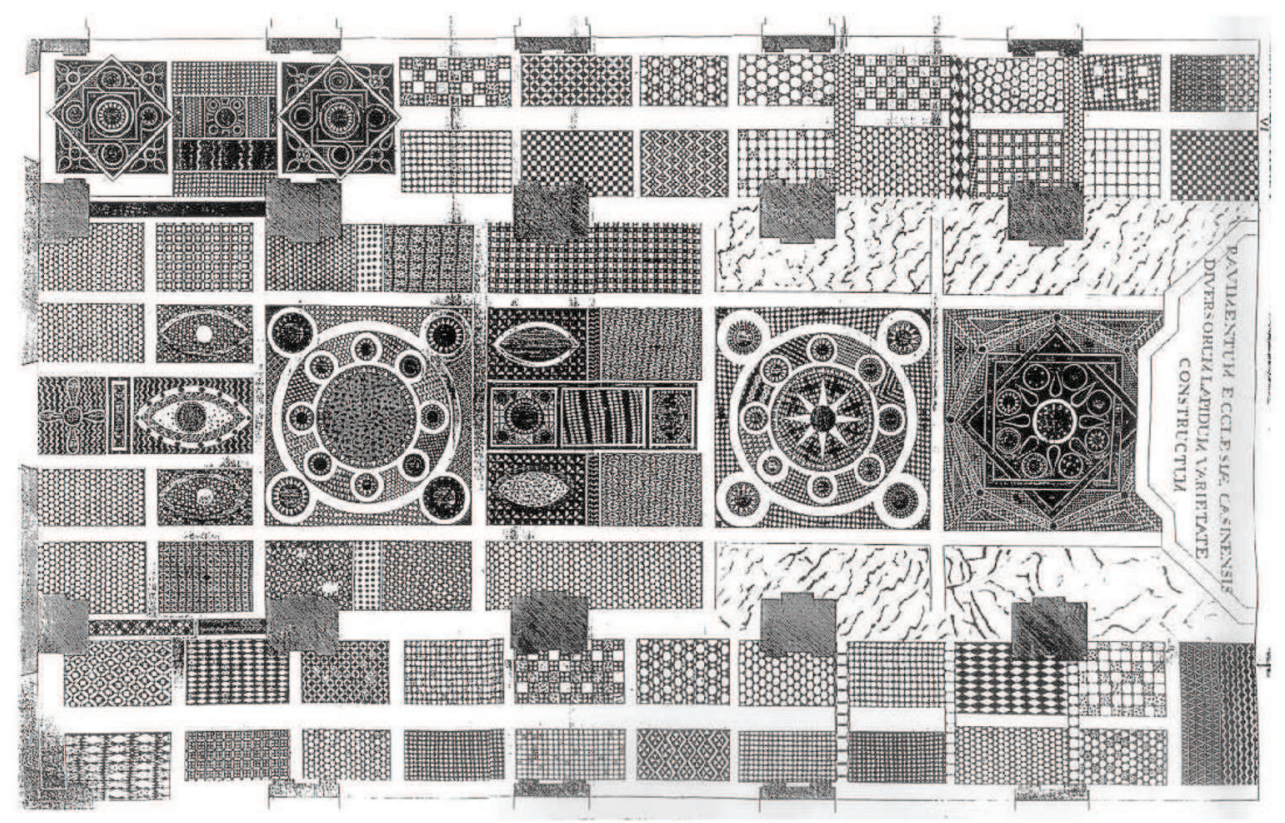

Fig. 11. Cosmatesque pavement of Montecassino Basilica in 1730 (Gattola, 1733).

The second survey was carried out by someone who is not well known, but is in fact one of the protagonists of the post-war reconstruction of Montecassino: Don Angelo Pantoni, monk and engineer, lived at Montecassino for over fifty years and carried out an in-depth study of the history of the monastery, reconstructing the events of its artistic and architectural life (Docci \& Cigola, 1995). The survey of the flooring is based on the tables found in the work by Gattola, but is more faithful to what must have been the original, including details that are definitely original, and were not included in the $18^{\text {th }}$-century engraved.

During reconstruction work, Don Angelo Pantoni was able to conduct important archaeological studies and made important finds from the Roman and late mediaeval periods of the complex, which had been hidden by subsequent constructions. This included most of Desiderio's floor, which had been thought lost, and allowed Pantoni to create image and photographic testimony of this floor before it was covered up once again. Indeed, most of the floor mosaic returned to oblivion in an inaccessible cavity beneath the new basilica reconstructed between 1948 and 1952; however but another section, consisting of a few dozen geometric design panels, was later repositioned in various chapels of the monastery. An analysis of the image testimony, Desiderio's floor appears to be a composition made of an orthogonal network of pale stone strips whose main purpose is organising the rhythmic flow of the composition sequence of the floor surface, as well as contributing to and 
alternating between the main elements of the architectural organism and the square sections of the Cosmatesque structure.

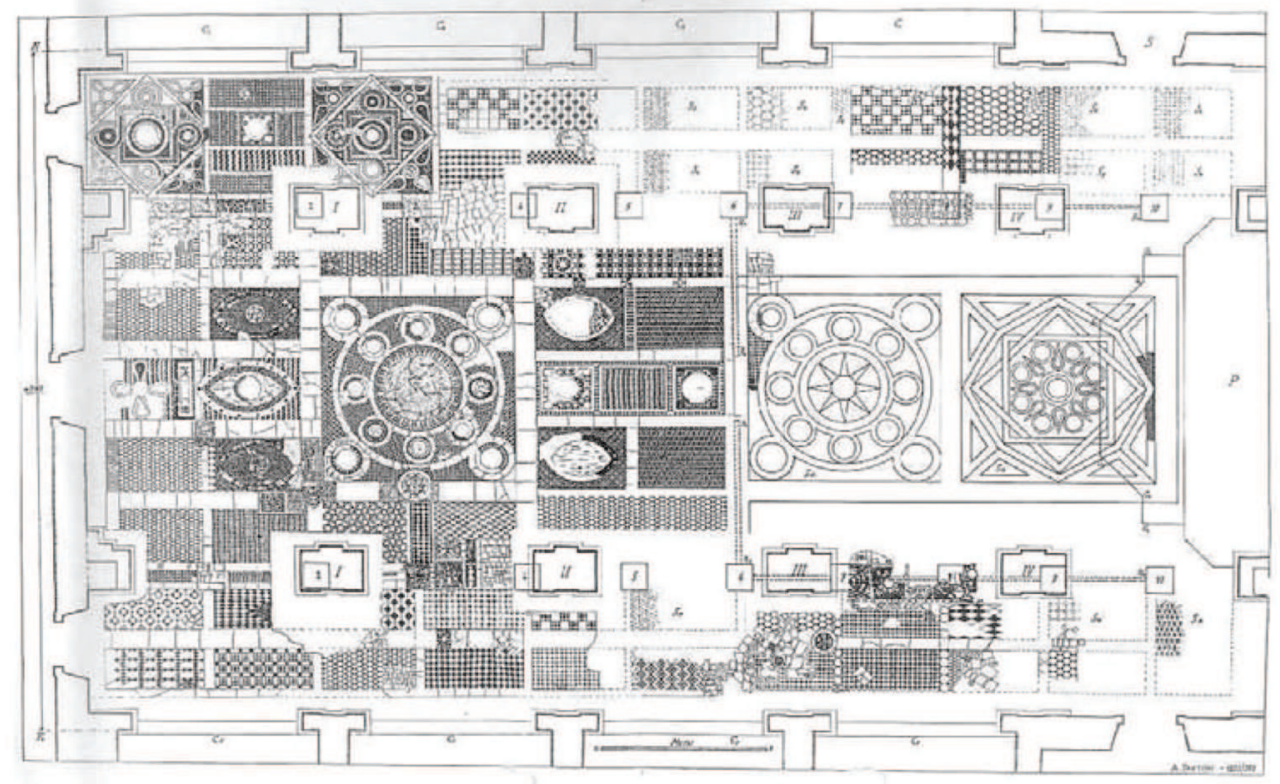

Fig. 12. Montecassino, cosmatesque pavement of basilica (1066/1071) beneath current in a survey of 1951-52. (Pantoni, 1972).

Pantoni's survey shows the entire floor surface as it was immediately after the destruction of the basilica by ally bombs. The structure of the entire composition, conditioned by the presence of the large central strip, consists of a series of sections differing in terms of dimension and decoration from those in the minor aisles, acting as a privileged walkway to the altar, marking it with sections that become more intricate as they lead towards the presbytery; in the side aisles, the surface was saturated using rectangular panels that are clearly inspired by the order of columns of Desiderio's mediaeval plan, rather than the Baroque version that replaced the $11^{\text {th }}$-century architecture.

The reconstruction plans of the abbey made in the early 1950s are useful for identifying where the mediaeval floor is today. The Italian government, in agreement with the Holy See, decided to reconstruct the Basilica immediately after the war, "where it was, the way it was and using the existing architectural and volumetric lines", as a means of social and historical affirmation and because, once the rubble was removed, it was seen that the foundations of the various buildings had not been undergone significant damage and it was possible to recover architectural remains and precious decorative fragments.

Reconstruction was based on the numerous drawings and surveys that the abbey that Pantoni had made in over ten years of work. These were used as to ensure that the reconstructed monument was the exact copy of the one destroyed by bombing. The image representations served as reconstruction plans and are preserved In the abbey library at Montecassino. They are defined in the scroll bearing the abbey coat of arms and the writing 
"Abbazia di Montecassino. Ricostruzione dell'Abbazia", and in one of these, a transversal section of the monastery, it is possible to fully understand the current position of the floor within the cavity beneath the floor reconstructed after the war (Cigola, 1997) .

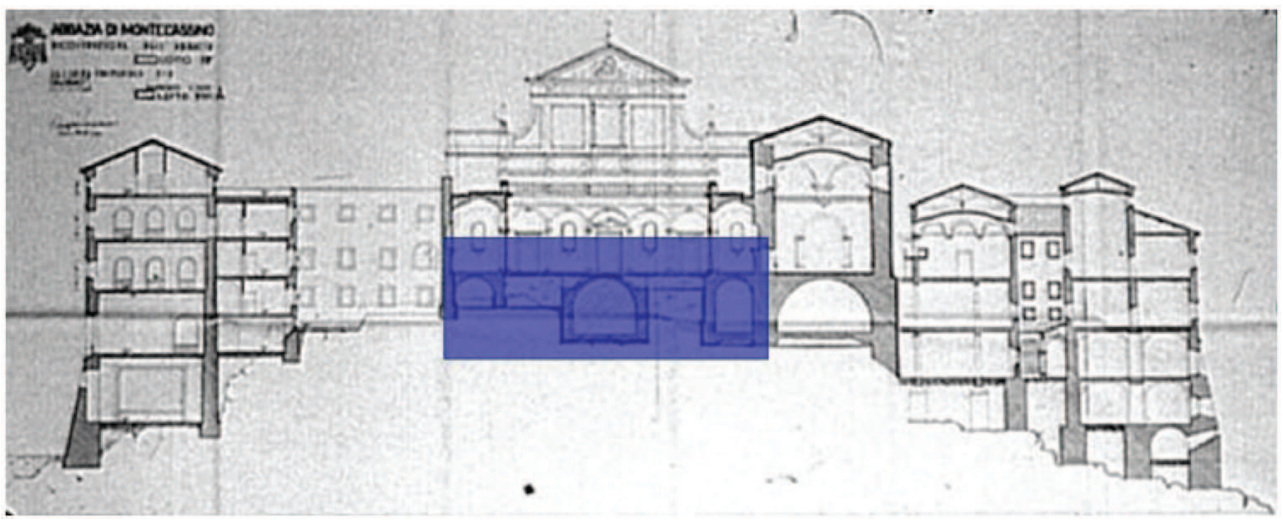

Fig. 13. Cross-section of reconstruction design for Montecassino Abbey (blue area indicates the area of ancient pavement)

In particular, figure 14, carried out during the excavations and surveys done before the start of reconstruction, highlights the difference in level of about one metre between Desiderio's floor and the current ground floor. Only available a very low cavity is available for inspections and other operations on the Cosmatesque mosaic, with no light or air and therefore unsuitable for work by humans. For this reason, after reconstruction of the new basilica, the floor was never inspected to analyse its state of health or carry out stylistic analyses of its decorations.
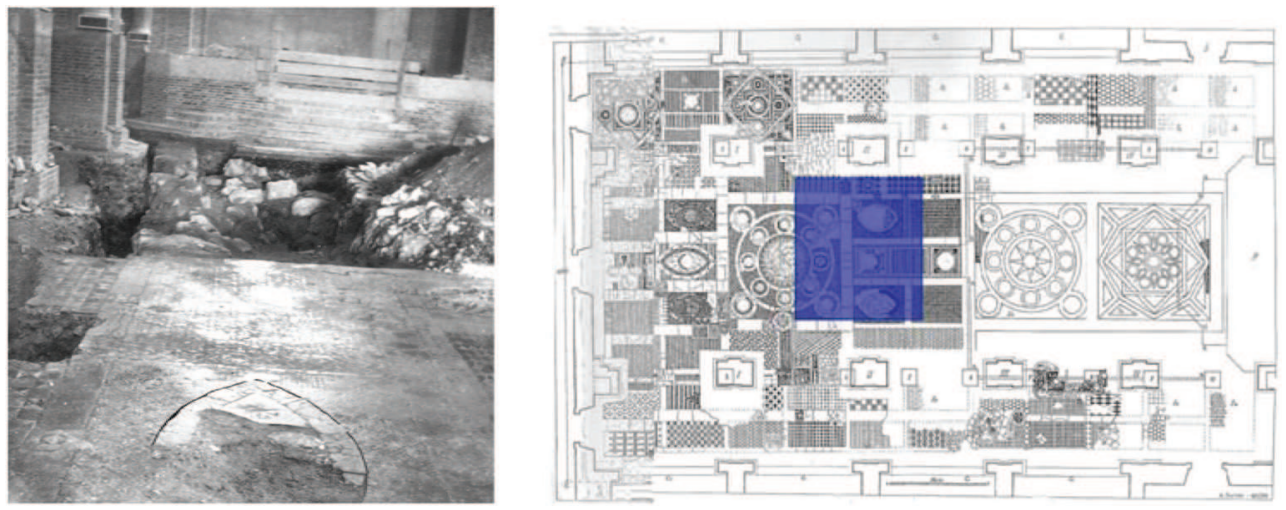

Fig. 14. A photo of the left side of the antique pavement before the reconstruction of the closed space in 1952 (Pantoni, 1951).

This case study is characterised by the impossibility of human operators to work a Survey activity and therfoere it is well suited to robot experimentation involving the analysis and conservation of a historical floor as an example of activity for architectural heritage. 
The needs of the DART team for Survey activity can be understood as requirements for the LARM team in designing structure and operations of robotic system. The robotic system must operate in the narrow environment while moving on the historical cosmatesque pavement with the aim to perform several survey operations by using suitable equipment. Thus, main characteristics for the robotic system can be outlined in a mobile platform carrying several instruments for survey of the pavement can be chosen for image capturing in terms of photos and videos, even for thermal inspection, laser scanner or other sensor for distance and orientation measures. Thus, this will require a certain volume available on board of the robotic system. Careful motion of the robotic system is expected in order to ensure full image capturing of the pavement and its environment and to avoid damage of the pavement itself or other components of the environment under exploration.

Once considered the above-mentioned conditions and constraint, it has been thought convenient to design a multilegged robot with a suitably large body and powered wheeled feet as shown in figure 15 .
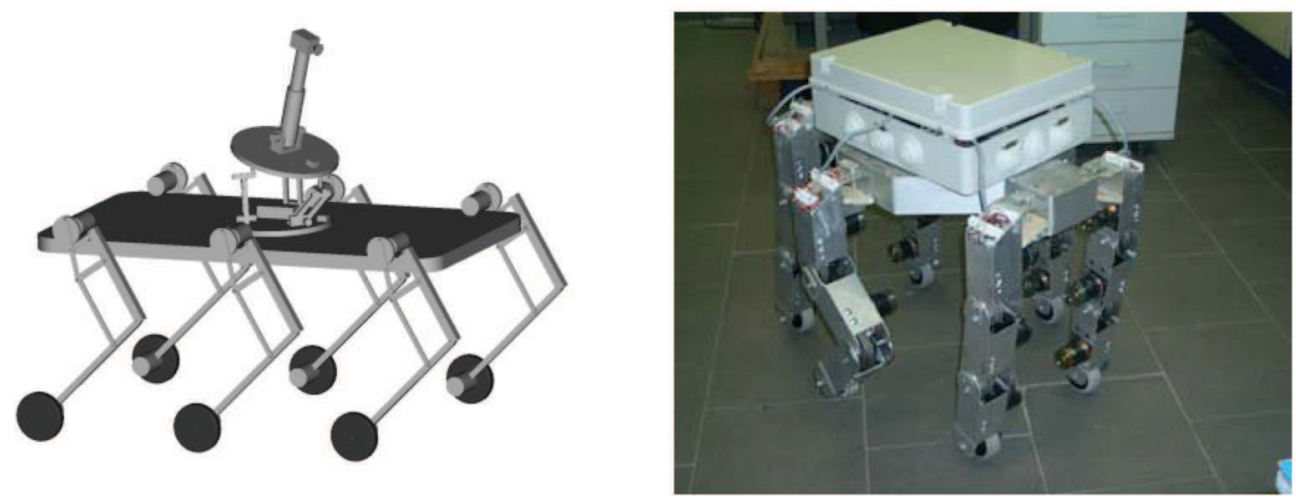

Fig. 15. The Cassino hexapod robot for Survey activity as a general kinematic scheme and a built prototype.

The idea of have several modular legs fulfils also requirements of low-cost design and easy operation features that are directed to permit implementation of the robotic moving platform even by the survey operators, once properly trained. Even with this aim, a simulation frame has been developed as shown in Fig, 16.

The design of Cassino hexapod robot has been developed by looking at the needs of Survey activity with several interactions involving also the above-mentioned simulations (Carbone, et al., 2007). In particular, the structure with six legs has been chosen in order to ensure contact with ground always with at last three feet so that a plane can be easily determinate for the robot body and survey equipment on it.

Powered wheeled feet are installed on the legs in order to have the possibility to smooth and regulate the contact force during the walking motion of the robot in order to prevent damage of the pavement surface and/or instable displacements. Once properly sensored the legs can be used also as a Survey equipment to measure the size (length and higth) of the area under Survey examination.

Virtual simulation by using virtual reconstruction of the environment has helped and will help to adjust and plan the survey operation wit proper feasibility and attention to the 
environment yet. Such a simulation is also helpful to reduce the time and effort of the laboratory test of a prototype, which is still underdevelopment for a practical on-field application. Althougt the Cassino hexapod robot for Survey activity is not yet read for operations, the work for its design and operation planning has permitted to achieve a good understanding between the two team of DART and LARm laboratiries towards a succesful application of robot in Survey an Conservation of historical architectural goods.

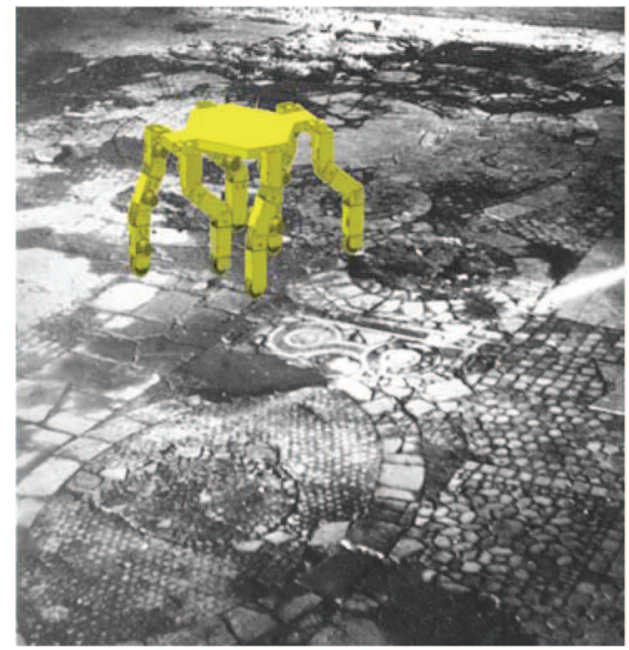

Fig. 16. A simulation example of operation of the designed Cassino hexapod robot for Survey activity

The interaction between the members of DART, experts in architectural surveying, will provide the main elements of the operations that the robot will have to perform inside the cavity of the Cosmatesque floor at Montecassino. These indications are thus put forward and made possible by the components of the LARM, experts in robotized systems.

These operations can be summed up as follows: the robot's first characteristic is its capacity to move within the area under examination, carrying image capturing equipment to perform the first analyses on the object: cameras for photographs and video; in a subsequent phase, this equipment must be replaced with more sophisticated instruments that can provide more precise information, such as thermal imaging equipment and laser scanners.

At the same time, since the floor in the cavity is extremely irregular due to the presence of architectural items from the same era and more ancient sections of the floor, in addition to forward motion the robot must also ensure that the image capturing equipment remains parallel to the floor. In addition to these characteristics, since knowledge of the current layout of the floor is extremely important for analysis and conservation purposes, the moving robot must be able to memorise and transmit the variation in the length of its legs during its journey to an external unit, in order to provide variations along the horizontal axis in real time, which will also provide a section of the floor at the same time.

To start experimenting the suitability of the elements proposed, these operations are being tested virtually, with simulation of the cavity and the floor surface, which can be recreated from the existing precise surveys carried out during reconstruction of the monastery. 
This type of monitoring, carried out in virtual 3D recreated by computer, is proving extremely useful, since it allows a reduction in time and costs in the planning phase, given that it is possible to thoroughly evaluate and test the model from the initial stage of design, operating within an environment that efficiently simulates the area in which the robot operates, allowing specific modifications and variations that would otherwise be cumbersome if carried out on a prototype.

\section{Conclusion}

The goal of this work is to test the possibility of designing robots and/or robotized system that are specifically dedicated to the field of cultural heritage and particularly to historical architecture. At the moment, our research is in the final stage of design of a robot, with activity that is carried out by the two LARM and RADET laboratories, with a continuous review of the needs that arise from the architectural application and from mechanical and mechatronic design.

Preliminary activity in Architecture Survey has been carried out at locale frame in Cassino with a construction of a very preliminary prototype and basic simulation experiences that were directed to the possibility to inspect and study the original cosmatesque Middle Ages pavement of Montecassino cathedral that is beneath the current pavement in a closed space with no air and no light. The mediaeval floor of Montecassino is an emblematic example of the interest and potentialities of using robotic systems in Architecture Survey, since it requires in-depth study to improve knowledge of the pavement that is not yet fully known. It is also necessary to further study the related documentation and analysis techniques for the safeguard and conservation of stone surfaces and ancient basilica of Montecassino, which lies hidden as enigmatic architectonic good beneath the current basilica.

\section{References}

Bertaux, E. (1904). L'art dans L'Italie meridionale, A. Fontemoig, Paris.

Carbonara, G. (1989). Disegnare per il restauro. Disegnare. Idee Immagini, No. 0, (ottobre 1989) (85-94), ISBN 88-7448-265-5

Carbone, G., et al., (2007) Operation strategy for a low-cost easy-operation Cassino Hexapod, Applied Bionics and Biomechanics, No. 4:4, (149-156). DOI: $10.1080 / 11762320802002573$

Ceccarelli, M., et al., (2002) A study of feasibility of using robots in architecture analisis and survey of a historical pavement, Proceedings of $11^{\text {th }}$ International Workshop on Robotics in Alpe-Adria-Danube Region, pp. 113-118, ISBN-963 715410 8, Balatonfired, june 2002, Budapest Polytechnic Editor, Budapest.

Ceccarelli, M. (2004) Fundamentals of Mechanics of Robotic Manipulation, Kluwer Academic Publishers, ISBN1-4020-1810k 2004, Dordrecht, The Netherlands

Cigola, M. (1993) Mosaici pavimentali cosmateschi: segni, disegni e simboli, Palladio, Vol. VI No. 11, (giugno 1993) (101-110).

Cigola, M. (1997) L'abbazia di Montecassino. disegni di rilievo e di progetto per la conoscenza e per la memoria, Disegnare. Idee Immagini, No. 14, (giugno 1997) (4352). ISBN 88-7448-819-k 
Cigola, M. (2005) L'abbazia benedettina di Montecassino. La storia attraverso le testimonianze grafiche di rilievo e di progetto, Ciolfi Editore, ISBN 88-86810-28-8, Cassino.

Cigola, M., et al., (2005). Application of robots for inspection and restoration of historical sites, Proceedings of 22st International Symposium on Automation and Robotics in Construction, CD, University of Ferrara, september 2005, Ferrara.

Cigola, M. \& Ceccarelli, M. (2006). Documentation and conservation of built heritage by using robot, Proceedings of XI International Seminar Forum Unesco Documentation for conservation and development. New heritage strategies for the future, pp. 64 - CD, ISBN- 10: 88-8453-494-1, University of Firenze, september 2006, University Press, Firenze.

Claussen, P.C. (1992). Marmi antichi nel Medioevo romano, L'arte dei Cosmati, In: Marmi antichi, G. Borghini, (Ed), (65-79), Leonardo-De Luca, ISBN 88-7813-265-9, Rome.

Della Marra, F. (1775) Descrizione istorica del monasterio di Monte Cassino per uso e comodo dei forestieri, Fratelli Raimondi, Napoli.

Docci, M. \& Cigola, M. (1995). Disegno come Memoria, memoria come disegno. L'Abbazia di Montecassino, Proceedings of Congresso Internazionale Il Disegno Luogo della Memoria, pp. 600-610, ISBN 88-8125-034-9, Firenze, settembre 1995; Alinea, Firenze.

Gattola E. (1733). Historia Abbatiae Casinensis, Sebastianum Coleti, Venezia.

Glass, D.F. (1980) Studies on Cosmatesque Pavements, Oxford British Archeological reports Series, No. 82, (1980) .

Gregorio Magno, (1924). Gregorii Magni Dialogi: libri 4, In: Fonti per la Storia d'Italia 57, U. Moricca, (Ed), (325-787), Tipografia del Senato, Rome.

Guidobaldi, F. \& Guiglia Guidobaldi A., (1983) Pavimenti marmorei di Roma dal IV al IX secolo. Studi di Antichitá Cristiana. Pontificio Istituto di Archeologia Cristiana, Vatican City.

Hoffmann, H. (1980). Chronica monasterii Casinensis, In: Monumenta Germaniae Historica. Scriptores XXXIV, Hahnsche Buchhandlung, ISBN - 3775253165, Hannover.

Pantoni, A., et al., (1951). Esplorazione archeologica, In Il sepolcro di s. Benedetto, Miscellanea Cassinese 27, Monastero di Monteassino, (Ed), (69-94), Sansaini, Rome.

Pantoni, A. (1972). Descrizione di Montecassino attraverso i secoli, In Benedictina XIX 2, (539586) Abbazia di Montecassino, Montecassino. 


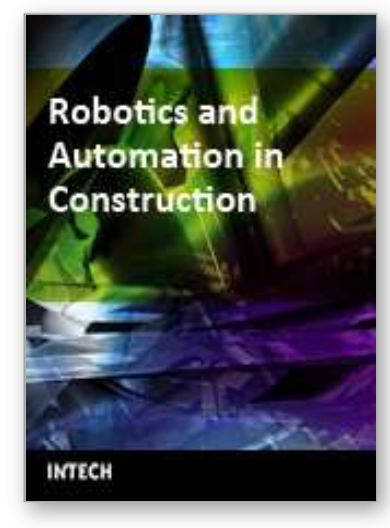

\author{
Robotics and Automation in Construction \\ Edited by Carlos Balaguer and Mohamed Abderrahim
}

ISBN 978-953-7619-13-8

Hard cover, 404 pages

Publisher InTech

Published online 01, October, 2008

Published in print edition October, 2008

This book addresses several issues related to the introduction of automaton and robotics in the construction industry in a collection of 23 chapters. The chapters are grouped in 3 main sections according to the theme or the type of technology they treat. Section I is dedicated to describe and analyse the main research challenges of Robotics and Automation in Construction (RAC). The second section consists of 12 chapters and is dedicated to the technologies and new developments employed to automate processes in the construction industry. Among these we have examples of ICT technologies used for purposes such as construction visualisation systems, added value management systems, construction materials and elements tracking using multiple IDs devices. This section also deals with Sensorial Systems and software used in the construction to improve the performances of machines such as cranes, and in improving Human-Machine Interfaces (MMI). Authors adopted Mixed and Augmented Reality in the MMI to ease the construction operations. Section III is dedicated to describe case studies of RAC and comprises 8 chapters. Among the eight chapters the section presents a robotic excavator and a semi-automated façade cleaning system. The section also presents work dedicated to enhancing the force of the workers in construction through the use of Robotic-powered exoskeletons and body joint-adapted assistive units, which allow the handling of greater loads.

\title{
How to reference
}

In order to correctly reference this scholarly work, feel free to copy and paste the following:

Michela Cigola and Marco Ceccarelli (2008). A Robot Application for Analysis, Survey and Conservation of Historical Architectures, Robotics and Automation in Construction, Carlos Balaguer and Mohamed Abderrahim (Ed.), ISBN: 978-953-7619-13-8, InTech, Available from:

http://www.intechopen.com/books/robotics_and_automation_in_construction/a_robot_application_for_analysis _survey_and_conservation_of_historical_architectures

\section{INTECH}

open science | open minds

\author{
InTech Europe \\ University Campus STeP Ri \\ Slavka Krautzeka 83/A \\ 51000 Rijeka, Croatia \\ Phone: +385 (51) 770447 \\ Fax: +385 (51) 686166
}

\author{
InTech China \\ Unit 405, Office Block, Hotel Equatorial Shanghai \\ No.65, Yan An Road (West), Shanghai, 200040, China \\ 中国上海市延安西路65号上海国际贵都大饭店办公楼 405 单元 \\ Phone: +86-21-62489820 \\ Fax: $+86-21-62489821$
}


www.intechopen.com 
(C) 2008 The Author(s). Licensee IntechOpen. This chapter is distributed under the terms of the Creative Commons Attribution-NonCommercialShareAlike-3.0 License, which permits use, distribution and reproduction for non-commercial purposes, provided the original is properly cited and derivative works building on this content are distributed under the same license. 